\title{
The Low Cost High Value Ceramic Colloidal Silver Filter: Household Water Treatment System
}

The initial ceramic filter for water treatment system had started in Nepal since 1987 AD by Hari Govinda Prajapati. He is a small- scale entrepreneur who lives and works in Thimi , Bhaktapur, a pottery community about 30 minutes outside of Kathmandu city. He is the owner and managing director of Madhyapur Clay Crafts and also Nepal Field Director of an US based NGO "Village Forward". This ceramic filter contains candle cylinder as the

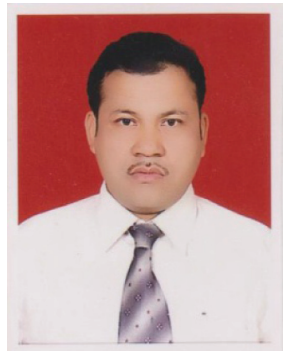

Hari Govinda Prajapati

hazardous and contaminated water was identified as a major cause of the epidemic. In every summer season, many people are affected by epidemic diseases caused by contaminated water in rural area of Nepal. If people use the ceramic colloidal silver filter which is cheap and more effective for water purifying, we can reduce the waterborne diseases considerably in Nepal.

filtration process; but is replaced by the disk filtration as new method since $2005 \mathrm{AD}$ by Madhyapur Clay Crafts with the collaboration of Solutions Benefiting Life, USA.

Mr. Prajapati has worked in this sector and given training to many people outside and inside the Kathmandu valley. People now are conscious in the health. Even rotary clubs, schools, and also in the rural area of the Nepal, the technology had been used and the demand of the filter has been increasing.

Combustible material is mixed with clay, and then fired in kiln for the filter disks. It is then immersed in a dilute colloidal silver solution. Completed filters are then tested to ensure proper flow rate and bacteria deactivation for more than 24 hours. It has capacity of 18 liters and filtering capacity is 4 liters $/ \mathrm{hr}$.

The ceramic colloidal silver filter system is one of the most effective and inexpensive method to purify the drinking water. It can be locally manufactured, easy to use and clean, low cost technology, and kills all the harmful bacteria. Laboratory test have indicated that this filters removes $99.9 \%$ of E-coli and other harmful bacteria. Thus, it would be more beneficial for the health consciousness of the people. It also helps for the minimization of the waterborne diseases since many people die of waterborne disease like diarrhea, cholera, typhoid, jaundice etc in the monsoon season.

In Nepal about 40,000 children below the age of five die every year due to lack of sanitation or say due to water borne diseases. In 2009, more than 200 people died of diarrhea epidemic (within an interval of few months) in the western parts of Nepal in the districts of Jajarkot, Rukum, Dailekh, Salyan, Dang and Rolpa (these are the remote districts of Nepal). Epidemiology and Disease Control Division of Nepal said that

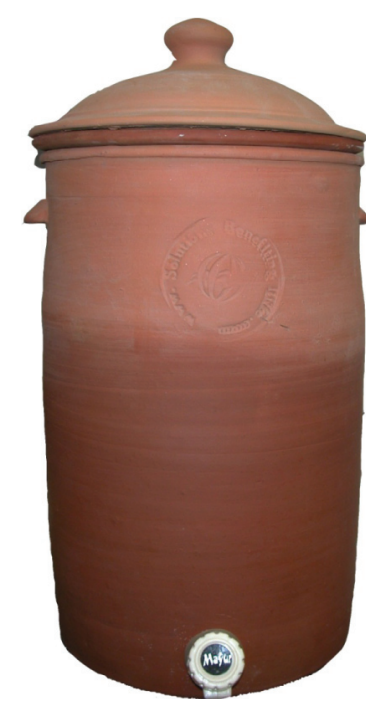

Nepali Silver treated water filter
In the Nepalese market there are several types of modern water filters available such as reverse osmosis, Ultra violet treatment, mineral water filters etc. These are expensive and the rural population can not afford them. Similar candle filter (stainless steel container, about 18 liters capacity) in the local market cost about Rs. 1100 (US\$15.5) per filter having 18 liters capacity. However, the ceramic filter under discussion is highly effective even though it is of simple technology. The main ceramic colloidal silver disk is made only in Madhyapur Clay Crafts, Thimi, Bhaktapur and other parts of the filter (mainly the container, filter holders and lids) are being manufactured in nine different places in Nepal. The beauty of this filter is that it can be manufactured locally and also in remote districts with some training. It will create jobs in the remote rural community and protect the health from water borne diseases. Moreover, it is a low cost filter costing about Rs.350/- to Rs.600/- per filter (US $\$ 5$ to 8.5) having capacity of 18 liters. Such low cost high value filters need to be popularized in the rural areas of Nepal and other developing countries.

Village Forward has been assisting for training, quality controlling and extension of filter production sites in various part of Nepal. The filter disk is patented in USA. Most of these filters are being sold through the local NGOs, women groups, Co-operative societies and pottery stores. The silver treated filter disks works for two years and these filters has to be replaced after 2 years of using. The filters are tested in laboratory of Village Forward in the USA and the local laboratories namely ENPHO (Environment and Public Health organization) and NESS (Nepal Environmental and Scientific Service), Kathmandu, Nepal.

Several teams of researchers such as from MIT, USA, preparing for their Degree thesis had come to Nepal and worked together with Mr. Prajapati in developing this filter. 